\title{
Impacto del fuego sobre la vegetación no vascular del suelo: un caso de estudio en los bosques de Polylepis australis (Rosaceae) del centro de Argentina
}

Fire impact on non vascular vegetation on soil: a case of study on Polylepis australis (Rosaceae) forests from central Argentina

\footnotetext{
Perazzo, Agostina; Juan M. Rodriguez *

Instituto de Investigaciones Biológicas y Tecnológicas (CONICET - Universidad Nacional de Córdoba) y Centro de Ecología y Recursos Naturales Renovables (FCEFyN - UNC). Av. Vélez Sarsfield 1611, Córdoba, Argentina.

* Autor corresponsal: juan.rodriguez@unc.edu.ar
}

\section{RESUMEN}

La vegetación no vascular está formada por líquenes, musgos, algas y cianobacterias tanto epífitas, como creciendo sobre el suelo. El objetivo de este trabajo fue estimar los cambios producidos por el fuego en la cobertura de briófitos y líquenes del suelo en parcelas de bosques de Polylepis australis (tabaquillo) en el Parque Nacional Quebrada del Condorito (PNQC) en el centro de Argentina. En un sector del Área Protegida incendiado en setiembre de 2015 se seleccionaron 40 parcelas de $30 \times 30$ $\mathrm{m}, 20$ en bosques no quemados y 20 en bosques quemados. Quince meses después del siniestro, en cada parcela se seleccionaron al azar cinco cuadrados de $2 \times 2 \mathrm{~m}$ para estimar cobertura en suelo diferenciando líquenes y briófitos. Además, se registraron la cobertura de plantas vasculares, suelo desnudo y mantillo. Como variables explicativas se midió la orientación y pendiente en cada cuadrado y en cada parcela. Además, se estimó la cobertura de bosque previo al incendio y la severidad del fuego. Los resultados muestran una muy baja superficie ocupada por líquenes y briófitos en el suelo afectado por el fuego a pesar de la recuperación de la vegetación vascular. La cobertura de líquenes y briófitos varían en función de características del micrositio

\footnotetext{
Ref. bibliográfica: Perazzo, A.; Rodriguez, J. M. 2019. "Impacto del fuego sobre la vegetación no vascular del suelo: un caso de estudio en los bosques de Polylepis australis (Rosaceae) del centro de Argentina". Lilloa 56 (2): 67-80. Fundación Miguel Lillo, Tucumán, Argentina. D.O.I.: doi.org/10.30550/j.lil/2019.56.2/6 > Recibido: 04/04/19 - Aceptado: 15/07/19 > URL de la revista: http://lilloa.lillo.org.ar

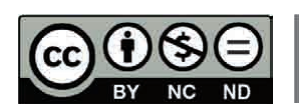

OPEN ${ }_{\text {ACCESS }}$ > Algunos derechos reservados. Esta obra está bajo una Licencia Creative Commons Atribución - No Comercial - Sin Obra Derivada 4.0 Internacional.
} 
tanto en parcelas quemadas como no quemadas. Se discute el posible impacto de la pérdida de esta cobertura en el ecosistema de bosque de Polylepis.

Palabras clave - Briófitos, incendios, líquenes, tabaquillo.

\section{ABSTRACT}

The non vascular vegetation is formed by lichens, mosses, algae and cyanobacteria, both epiphytic and growing on soil. The aim of this work was to estimate the impact of fire on the coverage of bryophytes and soil lichens in forest plots of Polylepis australis (Tabaquillo) in Quebrada del Condorito National Park (PNQC), in central Argentina. In a sector of the Protected Area in Setember 2015, 40 plots of 30 x 30 $\mathrm{m}$ were selected, 20 in unburned and 20 in burned forests. Fifteen months after the incident, five quadrates of $2 \times 2 \mathrm{~m}$ were randomly selected in each plot to estimate ground cover, differentiating lichens and bryophytes. In addition, the coverage of vascular plants, bare soil and mulch were recorded. As explanatory variables, orientation and slope of each square and plot measured. Furthermore, we estimated the forest cover before fire and fire severity. The results show a very low surface of the burned soli covered by lichens and bryophytes, despite the recovery of the vascular vegetation. Lichens and bryophytes coverage vary depending on the microsite characteristics, both in burned and unburned plots. Here, we discuss the possible impact of the loss of this coverage on forest ecosystem of Polylepis.

Keywords - Bryophytes, fire, lichens, tabaquillo.

\section{INTRODUCCIÓN}

En áreas montañosas del centro de Argentina (Sierras Pampeanas) el fuego es una herramienta de manejo que se utiliza para eliminar la biomasa seca acumulada de pastos y producir su rebrote para ser consumido por el ganado como forraje. En este escenario se considera que los bosques de Polylepis australis han quedado restringidos a valles profundos o quebradas producto de la ganadería y la alta frecuencia de incendios (Renison, Hensen, Suarez, Cingolani, 2006; Renison et al., 2015). En el ecosistema serrano el impacto del fuego sobre la vegetación vascular ha sido ampliamente estudiado (Renison, Cingolani, Suarez, 2002; Verzino et al., 2005; Giorgis, Cingolani, Cabido, 2013; Torres et al., 2014; Argañaraz et al., 2015; Arguibay y Renison, 2018), pero son pocos los estudios del impacto de los incendios sobre las comunidades de otros organismos y su recuperación luego de este disturbio (Longo, Nouhra, Goto, Berbara, Urcelay, 2014; Rodriguez et al., 2009).

En los bosques de Polylepis se desarrollan comunidades de organismos criptogámicos, principalmente líquenes y briófitos, muy diversas que utilizan como sustrato a los árboles, arbustos, rocas y suelo. La importancia de estos organismos en este ambiente se refleja en los endemismos encontrados y en la riqueza de especies descriptas (Rodriguez, Truong, Estrabou, Clerc, 2011; Rodriguez, Hernandez, Filippini, 
Cañas, Estrabou, 2016; Rodriguez, Filippini, Estrabou, Renison, 2017). Sin embargo, un rol clave pero menos estudiado, es la presencia de estos grupos formando parte de la cobertura criptogámica de la superficie del suelo. A nivel global, esta cobertura es responsable del $8 \%$ del ciclado del carbono y el $50 \%$ del nitrógeno que se fija en la superficie del planeta (Elbert et al., 2012). En el suelo, tiene un rol importante al estabilizar la superficie y, en consecuencia, reducir la erosión (Johansen, 1993). También existen evidencias sobre la influencia de la cobertura criptogámica en el establecimiento de plantas vasculares mediante procesos de facilitación para la retención de humedad o la protección de la semilla o la plántula principalmente en ecosistemas áridos y semiáridos (Belnap y Lange, 2001; Harper y Belnap, 2001; Peter, Leder, Funk, 2016), existiendo muy poca información en climas templados o de montaña (Calabrese y Rovere, 2013).

La recuperación de la vegetación en las montañas varía en relación a la altitud, la exposicioìn de ladera y la posicioìn topograìfica ya que estos factores condicionan la temperatura y la humedad de la superficie (Kulakowski y Veblen, 2002; Collins, Kelly, van Wagtendonk, Stephens, 2007). Por otra parte, el fuego puede causar daños severos en la cobertura del suelo y la recuperación depende de la intensidad, la frecuencia y el tiempo transcurrido desde el último evento (Hawkes, 2003). Por ejemplo, los incendios de baja intensidad no eliminan toda la estructura edáfica, permitiendo que la cobertura de vegetación no vascular se recupere sin pérdida significativa de suelo mientras que la recuperación luego de la pérdida total es un proceso lento, particularmente para líquenes y briófitos (Johansen y St. Clair, 1986). Además, a diferencia de pastizales, la quema de matorrales o bosques suelen ser más severos para la cobertura del suelo y su propia constitución (Johansen, 2001)

En este contexto se plantea como hipótesis que el fuego elimina la mayor parte de la cobertura de líquenes y briófitos del suelo en bosques, y la recuperación será exigua luego de 15 meses del siniestro a diferencias de las plantas vasculares no leñosas que evidencian igual superficie que sectores no quemados. La cobertura de líquenes y briófitos remanentes en el suelo de bosques quemados se modifica en función de la severidad del incendio y de las características topográficas de las parcelas de bosque. En bosques no quemados estas coberturas varían en función de las características de contexto a escala de parcela (orientación, pendiente y cobertura de bosque) y a micro escala (orientación, pendiente y cobertura de rocas). Para poner a prueba esta hipótesis, nos propusimos como objetivo estimar los cambios producidos por el fuego en la cobertura de briófitos y líquenes que crecen en el suelo en un sector del Parque Nacional Quebrada del Condorito (PNQC), en el centro de Argentina, quince meses después de ser afectado por un incendio.

\section{MATERIALES Y MÉTODOS}

\section{Área de estudio}

El Parque Nacional Quebrada del Condorito (PNQC) se encuentra en las Sierras Grandes de Córdoba (1700 a 2900 m snm, 31³4' S, 6450’ W), abarca una superficie 
de 34 mil ha y es la principal reserva hídrica de la región. Las temperaturas medias de los meses más fríos (mayo-setiembre) y más cálidos (octubre-Abril) son 5,0 y 11,4 ${ }^{\circ} \mathrm{C}$, respectivamente, sin período libre de heladas. La precipitación media anual es de $840 \mathrm{~mm}$, con la mayoría de las precipitaciones concentradas en los meses de verano, de octubre a abril (Cabido, 1985). Debido al clima estacional, el crecimiento de la vegetación se concentra en los meses cálidos y húmedos, mientras que el resto del año la vegetación permanece inactiva (Pucheta, Cabido, Díaz, Funes, 1998). Fitogeográficamente el área pertenece al distrito Chaqueño Serrano (Cabrera, 1976), no obstante, casi $50 \%$ de su flora es de linaje andino y patagónico y reúne además una diversidad rica en endemismos (Cabido, Funes, Pucheta, Vendramini, Diaz, 1998). La vegetación se presenta como un mosaico heterogéneo, en el que se reconocen diversas comunidades vegetales, entre las que se destacan bosques y matorrales de Polylepis australis y Maytenus boaria, pajonales gruesos de gramíneas dominadas por Poa stuckertii y pastizales altos y bajos dominados por gramíneas y hierbas bajas, tales como Deyeuxia hieronymi, Festuca spp. y Lachemilla pinnata (Cingolani, Renison, Zak, Cabido, 2004; Cingolani, Vaieretti, Gurvich, Giorgis, Cabido, 2010). Además, como resultado de la interacción entre los factores topográficos y la historia de uso ganadero son comunes los afloramientos rocosos y áreas erosionadas (Cingolani et al., 2004). El estudio se realizó en un sector del Parque Nacional libre de ganado desde el año 1996 y en el cual no se registraron incendios anteriores desde la fecha de la creación del área natural protegida.

\section{Diseño de los muestreos}

Se seleccionaron a campo y con la ayuda de imágenes satelitales 40 parcelas de $30 \times 30 \mathrm{~m}$, separadas por al menos $200 \mathrm{~m}$ entre si, 20 quemadas y 20 no quemadas, ubicadas entre los $31^{\circ} 41^{\prime} \mathrm{S}-64^{\circ} 46^{\prime} \mathrm{O}$ y $31^{\circ} 43^{\prime} \mathrm{S}-64^{\circ} 46^{\prime} \mathrm{O}$ y con un rango altitudinal de 2022 a $2112 \mathrm{~m}$, divididas en dos sectores (que se distanciaban en $4 \mathrm{~km}$ como mínimo) para tener una repetición del fenómeno en estudio (Fig. 1). Las parcelas quemadas se ubicaron en un área afectada por el incendio ocurrido en 2015, que abarcó casi 10000 hectáreas en el sector oeste del área protegida, impactando sobre bosque de Polylepis en el área intangible del Parque Nacional. Cada una se geoposicionó y se determinó la orientación y la pendiente con brújula y clinómetro. Además, mediante imágenes satelitales (Google Earth Pro 2015®) se estimó de manera visual la cobertura en \% de bosque de la parcela y esto luego se corroboró a campo siguiendo la metodología de Renison et al., (2006). Para las parcelas quemadas se determinó la cobertura de bosque previo al incendio utilizando las imágenes históricas más cercanas en el tiempo antes del siniestro (16/10/2014) y para las parcelas no quemadas se utilizaron las imágenes más nuevas disponibles (22/04 y 07/06 del 2016). Las parcelas seleccionadas tuvieron entre 40 y $85 \%$ de cobertura de bosque. Las parcelas fueron ubicadas de manera tal que la orientación de la pendiente (norte y sur principalmente) quede balanceada en la medida de lo posible (10 con orientación sur y 10 norte para las áreas quemadas y no quemadas). 

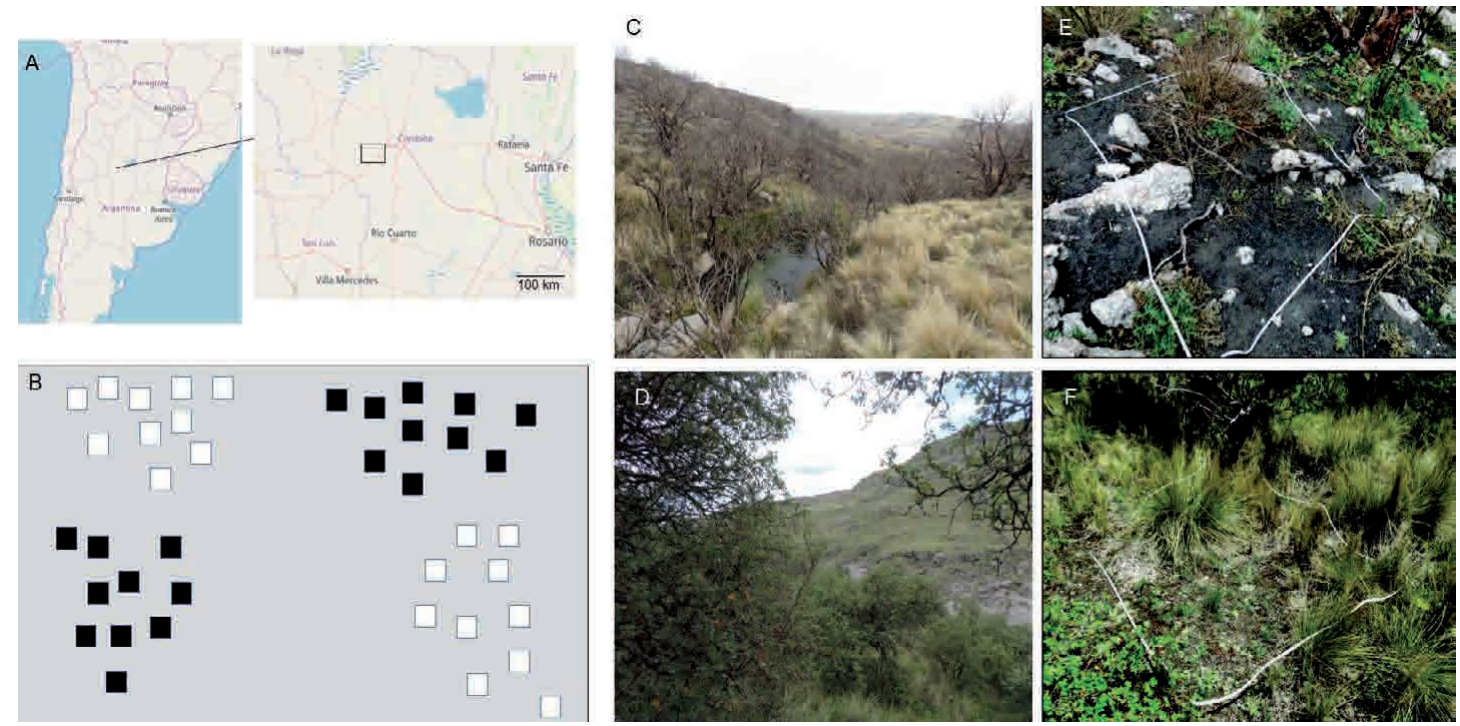

Fig. 1. A) Mapa del centro de Argentina y de la provincia de Córdoba ubicando el área de estudio (https://idecor-ws.cba.gov.ar/maps). B) Esquema representativo del diseño de muestreo: en negro parcelas en zonas quemadas y en blanco parcelas en zonas no quemadas con 20 parcelas de $30 \mathrm{x}$ 30 m en cada zona. $C$ y E) Parcela de $P$. australis y cuadrado de lectura en sector quemado. D y F) Parcela de $P$. australis y cuadrado de lectura en sector no quemado.

En cada parcela se seleccionaron aleatoriamente cinco cuadrados de lectura de 2 x $2 \mathrm{~m}$. Previamente se dejaron $5 \mathrm{~m}$ de margen en cada lado de la parcela para evitar el efecto borde (Kremsater y Bunnell, 1999). Dentro de cada cuadrado de lectura (100\%) se estimaron, de manera visual, las variables respuesta como el porcentaje de cobertura relativa de: líquenes, briófitos y la cobertura total (líquenes + briófitos). En esta estimación se incluyeron los líquenes y briófitos que crecían sobre rocas que estaban presentes dentro de los cuadrados de lectura. Estas rocas no son grandes afloramientos sino pequeños fragmentos que también soportan líquenes y briófitos. También, como un posible efecto del fuego en los cuadrados de lectura, se calculó la cobertura de plantas vasculares, mantillo y suelo desnudo de la misma manera que el resto de las estimaciones. Como variables explicativas se determinaron la cobertura de bosque (explicadas en el párrafo anterior) y la severidad de fuego de cada parcela y en cada cuadrado de lectura se midió la orientación (utilizando el coseno y seno para obtener el componente norte y este de la orientación), pendiente (en grados) y el \% de roca, como variables de micrositio.

Para estimar la severidad del incendio en las parcelas se utilizó un índice denominado en inglés: dNBR (multitemporal differenced Normalized Burn Ratio). La severidad del incendio se define como el grado de modificación que sufre la vegetación después del incendio (Diaz-Delgado, Llorett, Pons, Terradas, 2002). El índice se calcula como la diferencia temporal pre y post incendio entre el índice NBR, en consecuencia, es proporcional a la cantidad de biomasa consumida durante el incendio (Key y Benson, 2006). Este índice fue calculado por Landi (datos no publicados) a través de imágenes Landsat 8 LDCM (8 de agosto de 2014 y 13 septiembre 2015, escena 229-82, resolución espacial $30 \mathrm{~m}$ x $30 \mathrm{~m}$ ) quien determinó la severidad de este incendio en tres niveles: baja, media y alta. Sin embargo, al obtener solo una 
parcela con severidad baja esta categoría fue descartada del análisis. Finalmente se trabajó con siete parcelas de severidad media y doce alta.

\section{Análisis estadísticos}

Las variables respuesta obtenidas fueron: \% de cobertura de líquenes, briófitos, la suma de toda la cobertura no vascular del cuadrado de lectura y el \% de cobertura de plantas vasculares, mantillo y suelo desnudo. Se aplicó un Modelo Lineal Generalizado con distribución binomial considerando como factor fijo a la presencia o no de fuego y como factor aleatorio a la parcela de origen. Se utilizó la prueba a posteriori de DGC (DiRienzo et al., 2017). También, se modelaron las variables respuesta en función de la severidad de fuego pero solo para las parcelas quemadas. Por otra parte, se estimaron modelos para las parcelas quemadas y no quemadas por separado considerando a las variables explicativas como covariables. Las variables cuyo nivel de significación fue mayor a 0,05 fueron excluidas a la vez que se observó que estos modelos obtenidos tengan menor valor de AIC (criterio de Akaike) en comparación de aquellos que incluían a las variables no significativas (DiRienzo, Machiavelli, Casanoves, 2017). Se utilizó el programa Infostat junto con su interfase con R (DiRienzo et al., 2017).

\section{RESULTADOS}

Los resultados muestran que la cobertura de vegetación no vascular es de 4,68 \% de la superficie después de 15 meses del incendio; mientras que, en suelos no quemados, representa el 25,43 \% en promedio (Tabla 1, Fig. 2). Tanto briófitos como líquenes por separado disminuyeron significativamente su superficie cuando se compararon las parcelas quemadas de las no quemadas (Fig. 2). Por otra parte, la cobertura de plantas vasculares se recuperó casi en su totalidad no detectando diferencias significativas entre parcelas quemadas y no quemadas. En los sitios incendiados, el mantillo y suelo desnudo alcanzaron $23,60 \%$ y $12,95 \%$ respectivamente mientras que en las parcelas no quemadas estos valores fueron $46,99 \%$ y $4,04 \%$ (Tabla 1; Fig. 3). En

Tabla 1. Cobertura promedio en \% de líquenes, briófitos, cobertura total, plantas vasculares, mantillo y suelo desnudo en parcelas de Polylepis australis quemadas y no quemadas. Se indica el estadístico $\mathrm{F}$ y el valor $\mathrm{p}$ de los modelos lineales generalizados aplicados.

\begin{tabular}{lcccc}
\hline & No quemado & Quemado & Valor $F$ & $\mathrm{p}$ \\
\hline Líquenes & 13,32 & 1,54 & 36,52 & 0,0001 \\
\hline Briófitos & 12,11 & 3,15 & 29,13 & 0,0001 \\
\hline Total & 25,43 & 4,68 & 39,11 & 0,0001 \\
\hline Plantas vasculares & 60,79 & 53,86 & 3,00 & 0,0848 \\
\hline Mantillo & 46,99 & 23,60 & 30,43 & 0,0001 \\
\hline Suelo desnudo & 4,04 & 12,95 & 16,22 & 0,0001 \\
\hline
\end{tabular}




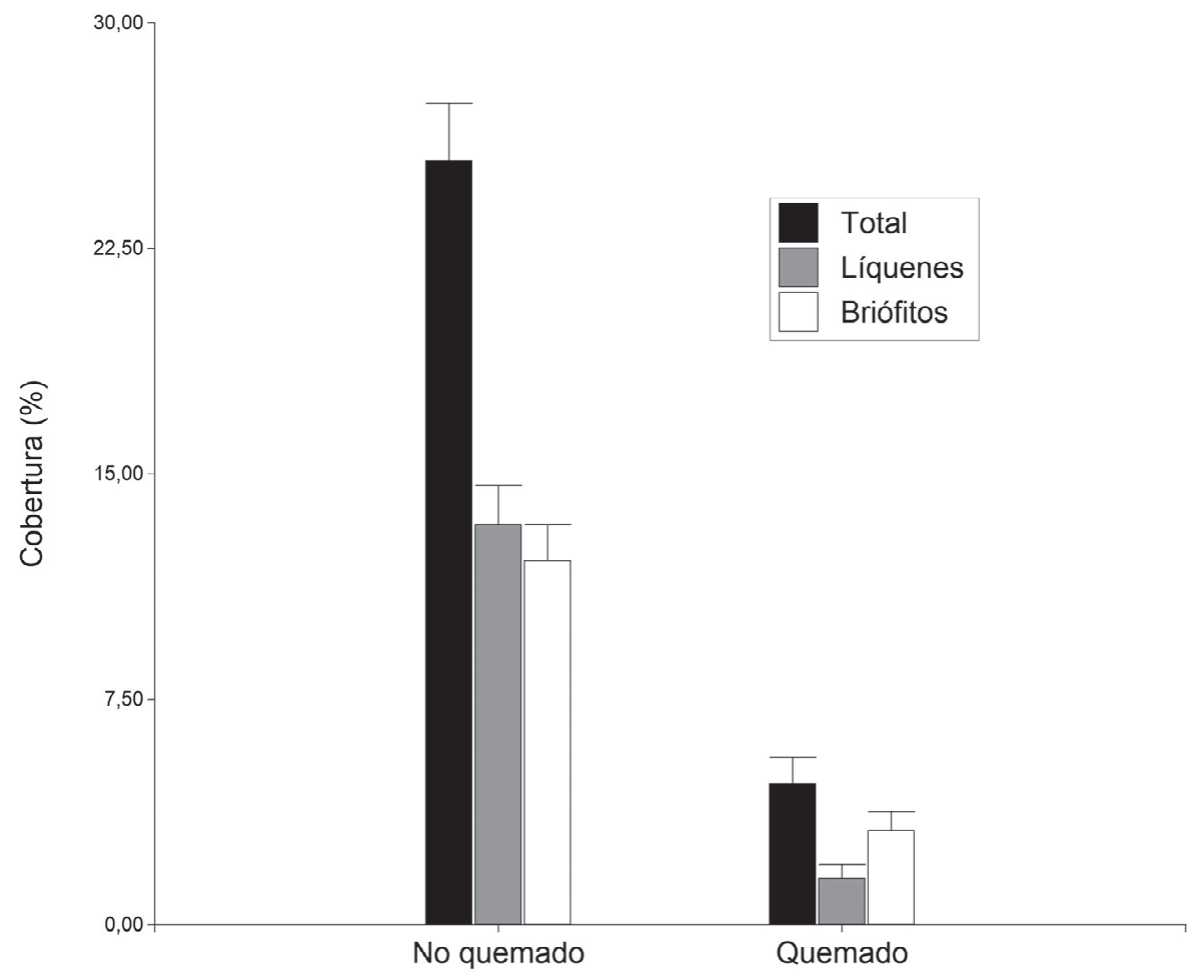

Fig. 2. Cobertura de vegetación no vascular (\%) promedio en parcelas de bosque de Polylepis australis no quemadas y quemadas para la cobertura total $(F=39,11, p=0,0001)$, líquenes $(F=36,52$, $p=0,0001)$ y briófitos $(F=29,13, p=0,0001)$ Las barras delgadas representan el error estándar.

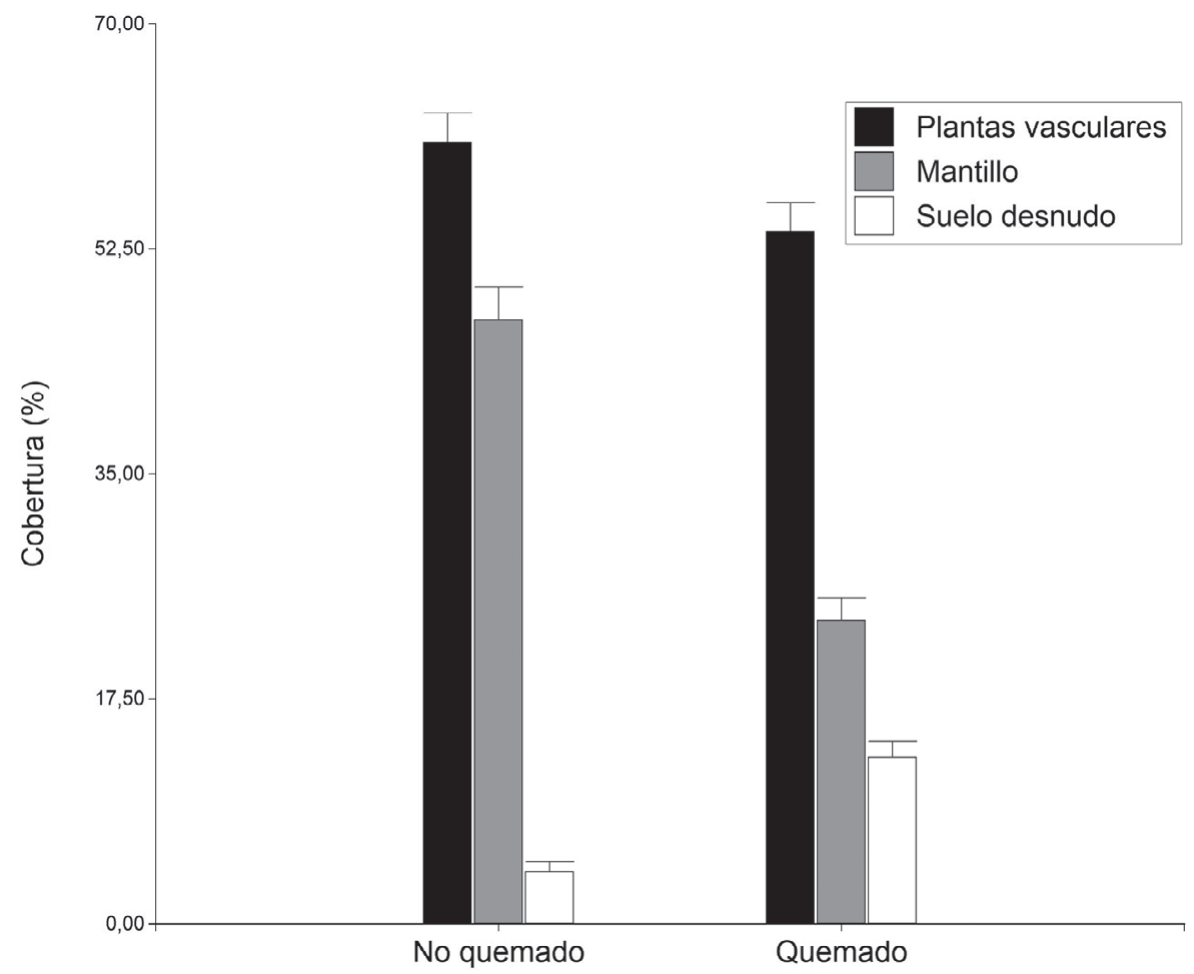

Fig. 3. Cobertura de plantas vasculares $(F=3,00, p=0,0848)$, mantillo $(F=30,43, p=0,0001)$ y suelo desnudo $(F=16,22, p=0,0001)$ en parcelas de bosque de Polylepis australis no quemadas y quemadas. Las barras delgadas representan el error estándar. 
cuanto a los niveles de severidad de fuego ninguna de las variables respuesta fue significativamente diferente $(\mathrm{p}=0,25)$ en función de este parámetro (Fig. 4).

Cuando analizamos, por separado, a las parcelas quemadas de las no quemadas, las variables explicativas que obtuvieron significancia estadística en los modelos obtenidos fueron a escala de micrositio (cuadrados de lectura, Tabla 2). Ninguna variable a nivel de parcelas (orientación, pendiente o superficie de bosque), influyeron en la cobertura de la vegetación no vascular. En todos los casos analizados, los cuadrados de lectura con mayor superficie de roca y mayor pendiente presentaron mayores valores de cobertura total. Por otra parte, la orientación solo fue significativa en los cuadrados de parcelas no quemadas para la cobertura total y los briófitos (Tabla 2).

\section{DISCUSIÓN}

La incidencia del fuego en los bosques de Polylepis australis es alta con un $60 \%$ de las localidades en donde se encuentra esta especie, con evidencias de haber sido quemadas (Renison et al., 2013) lo que provoca graves pérdidas para la biodiversidad que estos bosques sostienen. A partir de nuestros resultados, podemos conocer que otra consecuencia de este disturbio es la desaparición o disminución significativa de la cobertura de vegetación no vascular de la superficie, al menos en los primeros meses luego del siniestro. Este trabajo es el primero que trata sobre la presencia de

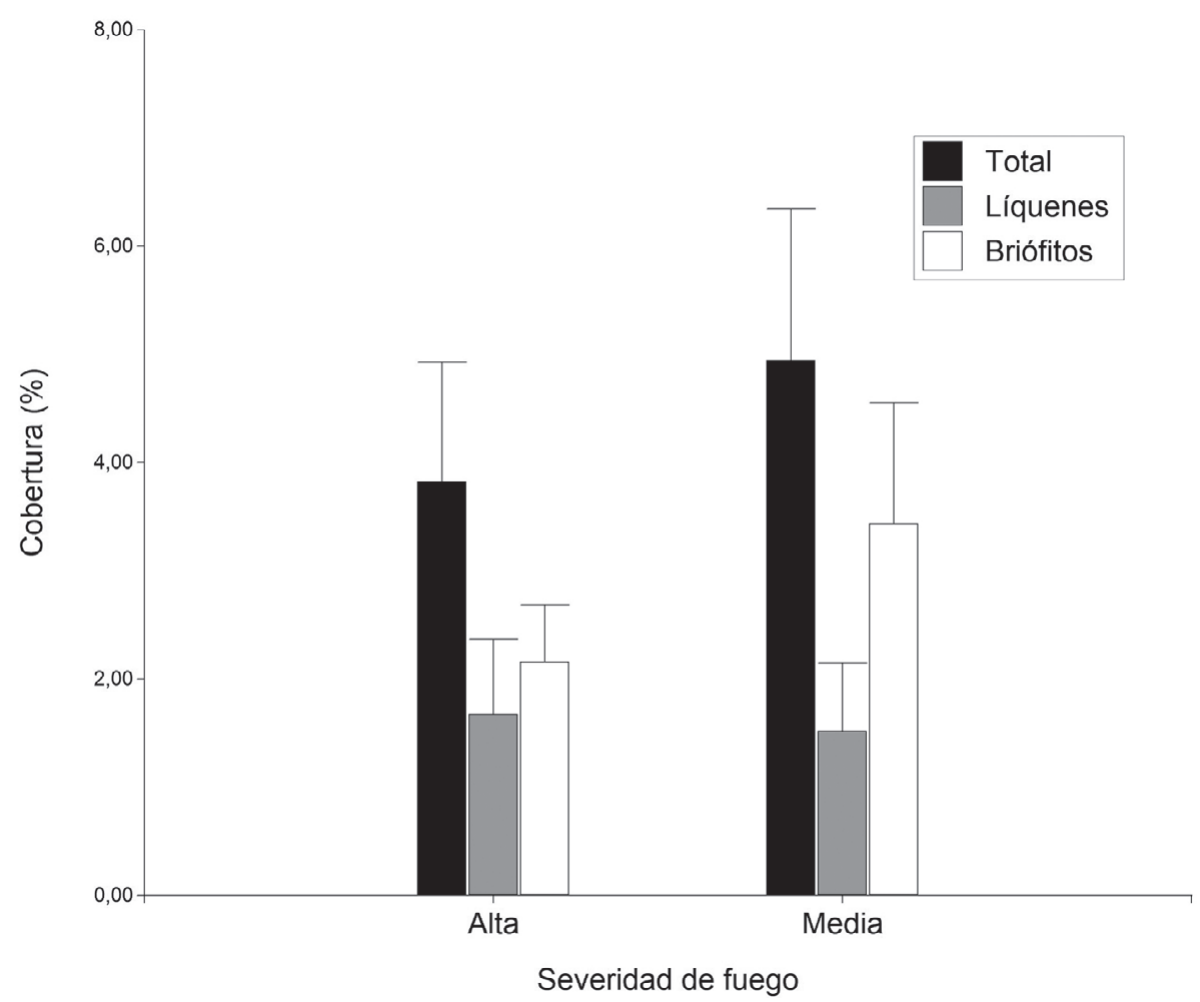

Fig. 4. Cobertura de vegetación no vascular (\%) promedio en parcelas de bosque de Polylepis australis quemadas según la severidad del fuego. Severidad alta $n=12$, media $n=7$. Las barras delgadas representan el error estándar. 
Tabla 2. Covariables con significancia estadística para modelos de distribución binomial considerando como variables respuesta a la cobertura de líquenes, briófitos y cobertura total en parcelas no quemadas y quemadas por separado. La pendiente, el \% de roca y la orientación son a escalas de micrositio (cuadrados de lectura).

\begin{tabular}{|c|c|c|c|c|}
\hline & $\begin{array}{l}\text { Variables } \\
\text { respuesta }\end{array}$ & Covariable & Valor F & $\mathrm{p}$ \\
\hline \multirow[t]{8}{*}{ No quemado } & \multirow[t]{2}{*}{ Líquenes } & Pendiente & 2,70 & 0,007 \\
\hline & & Roca & 20,33 & 0,0001 \\
\hline & \multirow[t]{3}{*}{ Briófitos } & Pendiente & 28,47 & 0,0001 \\
\hline & & Roca & 25,47 & 0,0001 \\
\hline & & Orientación & 29,50 & 0,0001 \\
\hline & \multirow[t]{3}{*}{ Total } & Pendiente & 40,43 & 0,0001 \\
\hline & & Roca & 46,63 & 0,0001 \\
\hline & & Orientación & 29,65 & 0,0001 \\
\hline \multirow[t]{6}{*}{ Quemado } & \multirow[t]{2}{*}{ Líquenes } & Pendiente & 28,56 & 0,0001 \\
\hline & & Roca & 90,58 & 0,0001 \\
\hline & \multirow[t]{2}{*}{ Briófitos } & Pendiente & 8,68 & 0,004 \\
\hline & & Roca & 82,79 & 0,0001 \\
\hline & \multirow[t]{2}{*}{ Total } & Pendiente & 34,60 & 0,0001 \\
\hline & & Roca & 192,24 & 0,0001 \\
\hline
\end{tabular}

una parte de la cobertura criptogámica en el suelo de bosques de Polylepis en relación al fuego. Trabajos realizados en zonas semiáridas reportaron el mismo patrón y una baja recuperación de briófitos y líquenes en suelos quemados luego de tres años (Johansen, 2001). En zonas de bosque más húmedas, la mayor cobertura de estos organismos se observó en sitios quemados cada cuatro años, formada principalmente por algas y cianobacterias. Sin embargo, briófitos y líquenes se recuperaron a los siete y trece años respectivamente desde el fuego, o bien, solo se observaron en sitios control sin incendios al menos en 40 años (Eldrige y Bradstock, 1994; Root, Brinda, Kyle Dodson, 2017).

En nuestro estudio, observamos que briófitos y líquenes ocupan aproximadamente el $20 \%$ de la superficie del suelo en bosques no quemados. Sin embargo, luego de 15 meses de ocurrido el incendio, la cobertura total queda reducida a menos del $5 \%$. En ese período, la vegetación vascular se recuperó notablemente al igual que el mantillo, mientras que el suelo desnudo presente en parcelas quemadas, es aproximadamente el valor de la cobertura no vascular en parcelas no quemadas. Esto indica que, en el tiempo estudiado, existe nula o poca recuperación de briófitos y líquenes dejando al suelo expuesto a la erosión, uno de los principales problemas ambientales en esta región montañosa del centro del país (Cingolani et al., 2013).

El nivel de severidad del fuego medido con información satelital no fue una variable que arrojara diferencias en la cobertura de briófitos y líquenes, al igual que observaron Root et al. (2017) en los bosques de la región SE de Estados Unidos. No obstante, es importante mencionar que solo se incluyeron parcelas incendiadas con severidad media y alta. Es probable que estos niveles de impacto sean muy altos para los organismos estudiados (Johansen, 2001) y que la alta frecuencia de estos incendios comprometa la diversidad de líquenes y briófitos en el suelo. Además, como se observó en los modelos obtenidos, las variables del micrositio como cobertura de rocas, 
orientación y pendiente influyeron positivamente en la cobertura de vegetación no vascular en parcelas quemadas y no quemadas. Esto nos permite hipotetizar que, a esa escala, un fuego de la magnitud del que ocurrió deja algunos espacios pequeños sin quemar, especialmente los más húmedos (orientaciones al sur y con más pendiente), en donde previamente ya había mayor cobertura de estos organismos (Johansen, 2001). Estas relaciones se vinculan con el grado de incidencia de la luz solar y la humedad, factores muy importantes para las comunidades de criptógamas a nivel de microhábitat, ya que encuentran mejores condiciones en sitios con menor insolación (Armesto y Contreras, 1981; John y Dale, 1990; Armstrong, 2002).

Asimismo, la cobertura de rocas en cada cuadrado fue un factor importante para explicar la mayor cobertura en parcelas quemadas y no quemadas. El aumento de la superficie de las rocas incrementa la oportunidad para el crecimiento de líquenes y briófitos, en particular, en este ambiente (Rodriguez et al., 2017). Observamos que en parcelas quemadas los cuadrados con más rocas presentaron mayor superficie ocupada por criptógamas, sugiriendo un efecto protector de las rocas. No obstante es muy baja la proporción de líquenes y briófitos encontradas en los sitios quemados como para asegurar este efecto. Por otra parte, pudimos determinar que los líquenes encontrados sobreviviendo en las rocas eran principalmente de hábito crustoso. A diferencia de otras formas de crecimiento foliosas y fruticulosas y presumiblemente también los briófitos, que se queman o quedan necrosadas (Rodriguez et al., 2009), los líquenes crustosos están completamente adheridos al sustrato y pueden evitar la ignición.

\section{CONCLUSIONES}

La vegetación no vascular en el suelo de bosques de $P$. australis es muy baja luego de 15 meses de ocurrido un incendio de severidad media y alta, dejando un porcentaje de la superficie descubierta y expuesta a la erosión. Variables de micrositio como la presencia de rocas, orientación o pendiente modifican la proporción de esta cobertura permitiendo en mayor o menor medida la supervivencia o recuperación. Futuros estudios deben establecer la relación entre este fenómeno y la erosión del suelo que queda descubierto, la tasa de recuperación de la cobertura y el posible vínculo con la restauración del bosque.

\section{AGRADECIMIENTOS}

Los autores agradecen al personal del Parque Nacional Quebrada del Condorito (PNQC) por la colaboración en las campañas de muestreo. Este trabajo fue parcialmente financiado por SECyT-UNC. Se agradece a Marcos A. Landi por la colaboración con los mapas de severidad de los incendios. Se accedió al PNQC mediante el permiso de investigación número: DRC 321. También agradecemos a los revisores por las sugerencias que enriquecieron el manuscrito. El segundo autor es investigador asistente del CONICET y director de este trabajo. 


\section{BIBLIOGRAFÍA / BIBLIOGRAPHY}

Argañaraz, J. P., Gavier Pizarro, G., Zak, M. y Bellis, L. M. (2015). Fire regime, climate, and vegetation in the Sierras de Córdoba, Argentina. Fire Ecology 11 (1): 55-73.

Argibay, D. D. y Renison, D. (2018). Efecto del fuego y la ganadería en bosques de Polylepis australis (Rosaceae) a lo largo de un gradiente altitudinal en las montañas del centro de la Argentina. Bosque 39 (1): 145-150. DOI: 10.4067/S071792002018000100014

Armesto, J. J. y Contreras, L. C. (1981). Saxicolous Lichen Communities: Non equilibrium Systems? The American Naturalist 118 (4): 597-604.

Armstrong, R. A. (2002). The effect of rock surface aspect on growth, size structure and competition in the lichen Rhizocarpon geographicum. Environmental and Experimental Botany 48 (2): 187-194.

Belnap, J. y Lange, O. L. (2001). Structure and functioning of biological soil crusts: a synthesis. En: J. Belnap, O. J. Lange, (Eds.), Biological Soil Crusts: Structure, Function, and Management. (pp. 471-479). Ecological Studies (Analysis and Synthesis), vol 150. Springer, Berlin, Heidelberg

Cabido, M. (1985). Las comunidades vegetales de la Pampa de Achala, Sierras de Córdoba, Argentina. Documents Phytosociologiques 9: 431-443.

Cabido, M., Funes, G., Pucheta, E., Vendramini, F. y Díaz, S. (1998). A chronological analysis of the mountains from Central Argentina. Is all what we call Sierra Chaco really Chaco? Contribution to the study of the flora and vegetation of the Chaco. XII. Candollea 53: 321-331.

Cabrera, A. L. (1976). Enciclopedia argentina de agricultura y jardinería. Fascículo 1, Regiones fitogeográficas argentinas. Editorial Acme S.A.C.I., Buenos Aires, Argentina.

Calabrese, G. M. y Rovere, A. E. 2013. El rol de los musgos en la germinación de especies leñosas: Implicancias de la heterogeneidad de micro-sitios para la restauración. Revista de la Asociación Argentina de Ecología de Paisajes 4 (2): 130-136.

Cingolani, A. M., Renison, D., Zak, M. R. y Cabido, M. (2004). Mapping vegetation in a heterogeneous mountain rangeland using Landsat data: an alternative method to define and classify land-cover units. Remote Sensing and Environment 92 (1): 84-97.

Cingolani, A. M., Vaieretti, M. V., Gurvich, D. E., Giorgis, M. E. y Cabido, M. (2010). Predicting alpha, beta and gamma plant diversity from physiognomic and physical indicators as a tool for ecosystem monitoring. Biological Conservation 143(11): 2570-2577.

Cingolani, A. M., Vaieretti, M. V., Giorgis, M. A., La Torre, N., Whitworth-Hulse J. I. y Renison, D. (2013). Can livestock and fires convert the sub-tropical mountain rangelands of central Argentina into a rocky desert?. Rangeland fournal 35: 285-297. 
Collins, B. M, Kelly, M., van Wagtendonk, J. M. y Stephens, S. L. (2007). Spatial patterns of large natural fires in Sierra Nevada wilderness areas. Landscape Ecology 22: 545-557.

Di Rienzo, J. A., Macchiavelli, R. A. y Casanoves, F. (2017). Modelos lineales generalizados mixtos: aplicaciones en InfoStat- 1a edición especial - Córdoba

Di Rienzo, J. A., Casanoves, F., Balzarini, M. G., Gonzalez, L., Tablada, M. y Robledo, C. W. (2017). InfoStat versión 2017. Grupo InfoStat, FCA, Universidad Nacional de Córdoba, Argentina. URL http://www.infostat.com.ar

Diaz-Delgado, R., Lloret, F., Pons, X. y Terradas, J. (2002). Satellite Evidence of Decreasing Resilience in Mediterranean Plant Communities after Recurrent Wildfires. Ecology 83 (8): 2293-2303.

Elbert, W., Weber, B., Burrows, S., Steinkamp, J., Büdel, B., Meinrat, O. A. y Pösch, U. . (2012). Contribution of cryptogamic covers to the global cycles of carbon and nitrogen. Nature Geoscience 5: 459-462.

Eldridge, D. J. y Bradstock, R. A. (1994). The effect of time since fire on the cover and composition of cryptogamic soil crusts on Eaucalyptus shrubland soil. Cunninghamia 3: 521-527.

Giorgis, M. A., Cingolani, A. M. y Cabido, M. (2013). El efecto del fuego y las características topográficas sobre la vegetación y las propiedades del suelo en la zona de transición entre bosques y pastizales de las sierras de Córdoba, Argentina. Boletín de la Sociedad Argentina de Botánica 48 (3-4): 493-513.

Google Earth Pro 2015®

Harper, K. T. y Belnap, J. (2001). The influence of biological soil crusts on mineral uptake by associated vascular plants. Fournal of Arid Environments 47 (3): 347357.

Hawkes, C. V. (2003). Microorganismos del suelo, plantas en peligro de extinción y la conservación del Matorral de Florida. Ecosistemas 12 (2): 1-6.

Johansen, J. R. y St. Clair, L. L. (1986). Cryptogamic soil crusts: recovery from grazing near Camp Floyd State Park, Utah, USA. Great Basin Naturalist 46 (4): 632-640.

Johansen, J. R. (1993). Cryptogamic crusts of semiarid and arid lands of North America. Fournal of Phycology 29 (2): 140-147.

Johansen, J. R. (2001). Impacts of Fire on Biological Soil Crusts. En: J. Belnap, O. J. Lange, (Eds.), Biological Soil Crusts: Structure, Function, and Management. (pp. 285-387). Ecological Studies (Analysis and Synthesis), vol 150. Springer, Berlin, Heidelberg

John, E. y Dale, M. R. T. (1990). Environmental correlates of species distributions in a saxicolous lichen community. Fournal of Vegetation Science 1 (3): 385-392.

Key, C. H. y Benson, N. C. (2006). Landscape Assessment- Sampling and Analysis Methods. En: D. C. Lutes (Ed.), FIREMON: Fire Effects Monitoring and Inventory System. United States Department of Agriculture Forest Service. Fort Collins, USA.

Kremsater, L. y Bunnell, F. L. (1999). Edge effects: Theory, evidence and implications to management of western North American forests. En: J. Rochelle, L. Lehmann, J. L. 
Kulakowski, D. y Veblen, T. T. (2002). Influences of fire history and topography on the pattern of a severe wind blowdown in a Colorado Subalpine Forest. Fournal of Ecology. 90: 806-819.

Longo, S., Nouhra, E., Goto, B., Berbara, R. y Urcelay, C. (2014) Effects of fire on arbuscular mycorrhizal fungi in the Mountain Chaco Forest. Forest Ecology and Management 315: 86-94.

Peter, G., Leder, C. V. y Funk, F. A. (2016). Effects of biological soil crust and water availability on seedlings of three perennial Patagonian species. Fournal of Arid Environments. 125: 122-126.

Pucheta, E., Cabido, M., Díaz, S. y Funes, G. (1998). Floristic composition, biomass, and aboveground net plant production in grazed and protected sites in a mountain grassland of central Argentina. Acta Oecologica 19 (2): 97-105.

Renison, D., Cingolani, A. M., Suarez, R. (2002). Efectos del fuego sobre un bosquecillo de Polylepis australis (Rosaceae) en las montañas de Córdoba, Argentina. Revista Chilena de Historia Natural 75 (4):719-727.

Renison, D., Hensen, I., Suárez, R. y Cingolani, A. M. (2006). Cover and growth habit of Polylepis woodlands and shrublands in the mountains of central Argentina: human or environmental influence? Fournal of Biogeography 33 (5): 876-887.

Renison, D. (2013). Can livestock and fires convert the sub-tropical mountain rangelands of central Argentina into a rocky desert? The Rangeland Fournal 35: 285-297.

Renison, D., Cuyckens Griet, A. E., Pacheco, S., Guzmán, G., Grau, H., Marcora, P., Robledo, G., Cingolani, A. M., Dominguez, J., Landi, M., Bellis, L. y Hensen, I. (2013). Distribución y estado de conservación de las poblaciones de árboles y arbustos del género Polylepis (Rosaceae) en las montañas de Argentina. Ecología Austral 23 (1): 27-36.

Renison, D., Chartier, M. P, Menghi, M., Marcora, P., Torres, R.C., Giorgis, M., Hensen I., Cingolani, A. M. (2015). Spatial variation in tree demography associated to domestic herbivores and topography: insights from a seeding and planting experiment. Forest ecology and management 335: 139146.

Rodriguez, J. M., Estrabou, C., Fenoglio, R., Robbiati, F., Salas, M. C. y Quiroga, G. (2009). Recuperación post-fuego de la comunidad de líquenes epífitos en la provincia de Córdoba, Argentina. Acta Botánica Brasilica 23 (3): 854-859.

Rodriguez, J. M., Estrabou, C., Truong, C. y Clerc, P. (2011). The saxicolous species of the genus Usnea subgenus Usnea (Parmeliaceae) in Argentina and Uruguay. The Bryologist 114 (3): 504-525.

Rodriguez, J. M., Hernandez, J. M., Filippini, E., Cañas, M. y Estrabou, C. (2016). Nuevas citas de macrolíquenes para Argentina y ampliaciones de distribución en el centro del país. Boletín de la Sociedad Argentina de Botánica 51 (3): 405417.

Rodriguez, J. M., Renison, D., Filippini, E. y Estrabou, C. (2017). Climate change in the mountains: insights from a study of saxicolous lichen communities in relation to altitude and microsite. Biodiversity and Conservation 26: 1199-1215. DOI 10.1007/s10531-017-1293-0 
Root, H. T., Brinda, J. C. y Kyle Dodson, E. (2017). Recovery of biological soil crust richness and cover 12-16 years after wildfires in Idaho, USA. Biogeosciences 14: 3957-3969.

Torres, R. C., Giorgis, M. A., Trillo, C., Volkmann, L., Demaio, P., Heredia, J. y Renison, D. (2014). Post-fire recovery occurs overwhelmingly by resprouting in the Chaco Serrano forest of Central Argentina. Austral Ecology 39 (3): 346354.

Verzino, G., Joseau, J., Dorado, M., Gellert, E., Rodríguez Reartes, S. y Nóbile, R. (2005). Impacto de los incendios sobre la diversidad vegetal, Sierras de Córdoba, Argentina. Ecología Aplicada 4 (1-2): 25-34.

Wisniewski, (Eds.), Forest fragmentation: wildlife and management implications, (pp. 117-153). Brill, Leiden, Germany. 